\title{
Design criteria for rotating flow cells in rectangular aquaculture tanks
}

\author{
Joan Oca* , Ingrid Masaló \\ Departament d'Enginyeria Agroalimentària i Biotecnología, Universitat Politècnica de Catalunya (U.P.C.), Centre de \\ Referència en Aqüicultura de la Generalitat de Catalunya, Av. Canal Olímpic s/n, 08860 Castelldefels, Spain
}

Received 23 November 2005; accepted 15 June 2006

\begin{abstract}
This work analyzes the simplest inlet and outlet configurations that create homogeneous rotating flow cells in rectangular aquaculture tanks, in order to combine the advantages of rectangular and circular tanks. All the configurations analyzed had a single jet discharge per rotating flow cell, with the drain placed in the center of each rotating flow cell. Length/width ratios $(L / W)$ of 0.95 , 1.43 and 1.91 were tested. In addition, the effect of placing oblique baffles in the walls to redirect the water currents was assessed. Experiments were conducted in a laboratory-scale tank with a Reynolds number of approximately 6000. Particle tracking velocimetry techniques were used to characterize the flow pattern in a horizontal cross-section at the midpoint of the water depth. A tank resistance coefficient $\left(C_{\mathrm{t}}\right)$ was defined in order to characterize the resistance offered by each tank configuration to the circulation of water. Results indicated that when $L / W$ was increased from 0.95 to 1.43 , the main vortex that was formed occupied most of the rotating cell area and did not create significant dead volumes in the tank. A $L / W$ ratio of 1.91 dramatically reduced flow uniformity and hardly increased $C_{\mathrm{t}}$ values. The presence of baffles contributed to high velocities in the area around the center drains and decreased $C_{\mathrm{t}}$ values by 30-35\%. Higher velocities are critical to the self-cleaning properties of the tank. The calculation of a $C_{\mathrm{t}}$ value makes it easier to obtain the desired average velocities in the tank by adjusting the water exchange rate and the water jet discharge velocity.
\end{abstract}

(C) 2006 Published by Elsevier B.V.

Keywords: Aquaculture tank design; Rotating flow cells; Baffles; Length/width ratio

\section{Introduction}

The selection of tank geometry in inland aquaculture systems is essential in order to ensure optimal fish culture conditions, minimal waste discharge into the environment and easier management of fish farms. Two main geometries are used in the construction of aquaculture tanks: rectangular and circular. In general, rectangular tanks are easier to handle and clean than circular tanks. Nevertheless, low velocities and poor

\footnotetext{
* Corresponding author. Tel.: +34 935521223; fax: +34 935521001 . E-mail address: joan.oca@upc.edu (J. Oca).
}

mixing of water in rectangular tanks lead to the creation of dead volumes, which in turn cause the accumulation of biosolids (faecal solids and uneaten feed) on the tank bottom. These biosolids increase the biochemical oxygen demand and produce large gradients in dissolved oxygen and fish metabolites, which can create disparities in fish distribution and fish quality (Watten and Beck, 1987).

In circular tanks, water is injected tangentially to achieve higher velocities and create mixing flow conditions (Levenspiel, 1979). This type of flow generates more homogeneous water quality throughout the tank and allows for a more uniform distribution of fish (Ross et al., 1995; Ross and Watten, 1998). Higher 
velocities create self-cleaning conditions by rapidly displacing biosolids to the central outlet (Timmons et al., 1998). Furthermore, dual drain systems can easily be adapted to circular tanks to obtain two separate effluents, one of them removing approximately 5-20\% of recirculating water from the center of the tank bottom, but containing $80-90 \%$ of the suspended solids (Van Toever, 1997; Lunde et al., 1997; Schei and Skybakmoen, 1998; Summerfelt et al., 2000; Davidson and Summerfelt, 2004). Dual drains simplify water treatment and are particularly suited to recirculating aquaculture systems. Wong and Piedrahita (2003) and Lareau et al. (2004) suggested some equivalent devices for raceways, but these are not widely used on a commercial scale. Another important advantage provided by circular tanks is possibility of adjusting water velocity to the desired fish swimming speed, which will depend on the species and the size of fish (Woodward and Smith, 1985; Watten and Johnson, 1990; Timmons and Youngs, 1991; Losordo and Westers, 1994).

Several attempts have been made to combine the hydrodynamic advantages of circular tanks and the handling advantages of raceways. Vertical baffles, installed perpendicular to the water flow, increased bottom velocities and reduced biosolid accumulation but interfered with fish handling and in some cases caused behavioral problems (Boersen and Westers, 1986; Kindschi et al., 1991; Wagner, 1993; Barnes et al., 1996; True et al., 2004). In another approach, a pipe placed along the bottom of one side of the raceway jetted water along the tank bottom, thus establishing rotary circulation on the longitudinal axis of the tank. This provided self-cleaning properties (Watten and Beck, 1987; Watten and Johnson, 1990) but the costs of tank construction were high.

One particularly important development was the "rectangular mixed-cell rearing unit" proposed by Watten et al. (2000), in which vortex cells were created within a rectangular raceway by directing four water jets tangentially to each cell, thereby establishing rotary circulation. In addition, drains were placed in the center of each cell, with a distance between outlets equal to the tank width. The mixing flow characteristics of these rectangular tanks were comparable to those observed in circular tanks. Similar flow characteristics were also obtained by Oca et al. (2004) and Masaló and Oca (2004) in a rectangular tank with only one tangential water inlet per cell.

Tvinnereim (1988) and Tvinnereim and Skybakmoen (1989) studied the influence of inlet design and impulse force on the current velocity and flow distribution in circular and octagonal tanks. The circulating velocity and transport capacity of the water for the removal of particles from the tank bottom were controlled by adjusting the impulse force $F_{\mathrm{i}}$ (Eq. (1)) of the inflowing water:

$F_{\mathrm{i}}=\rho Q\left(V_{2}-V_{1}\right)$

where $\rho$ is the density of water, $Q$ the injected water flow rate and $V_{1}$ and $V_{2}$ are the mean circulating velocity in the tank and the jet velocity from the inlet, respectively.

The aim of this work was to analyze the simplest inlet and outlet configurations in rectangular aquaculture tanks that create homogeneous rotating flow cells, combining the advantages of both rectangular raceways and circular tanks. Each cell would therefore consist of a large vortex occupying the entire tank width with individual cells aligned on the longitudinal tank axis. Several configurations were tested to evaluate the effect of water discharge jets, the separation of drains and placing oblique baffles in the walls to divert the water currents. The measured velocity magnitudes and uniformities in the rotating flow cells were compared with those obtained in a circular tank.

\section{Material and methods}

\subsection{Tank configurations}

Experiments were carried out using a rectangular tank $200 \mathrm{~cm}$ long and $35 \mathrm{~cm}$ wide. A circular tank with a diameter of $49 \mathrm{~cm}$ was used for comparison. Water depth was maintained at approximately $6 \mathrm{~cm}$ in both systems. Water was circulated using a pump equipped with a variable speed motor, allowing adjustment of inlet discharge jets rates.

The selected water inlet configuration consisted of a single water jet entry for each rotating cell to ensure simple construction and the possibility of adaptation to existing rectangular tanks. Water jet depths were $3 \mathrm{~cm}$. Drains were located in the center at the bottom of each rotating cell area (Fig. 1).

Three cell length/width ratios $(L / W)$ were analyzed: $0.95,1.43$ and 1.91 , corresponding to 6,4 and 3 vortices for the total tank length. In addition, the effect of oblique baffles that diverted the water currents was evaluated. Three configurations were tested: without baffles, with baffles in one side wall and with baffles in both side walls. The baffles were placed in the midpoint between two opposite water inlets (Fig. 2) at an inclination of $45^{\circ}$ with the lateral wall. Baffles were separated by a distance equal to twice their length, allowing them to be turned and aligned with the wall for easier manipulation of fish and permitting longitudinal flow in specific circumstances. 


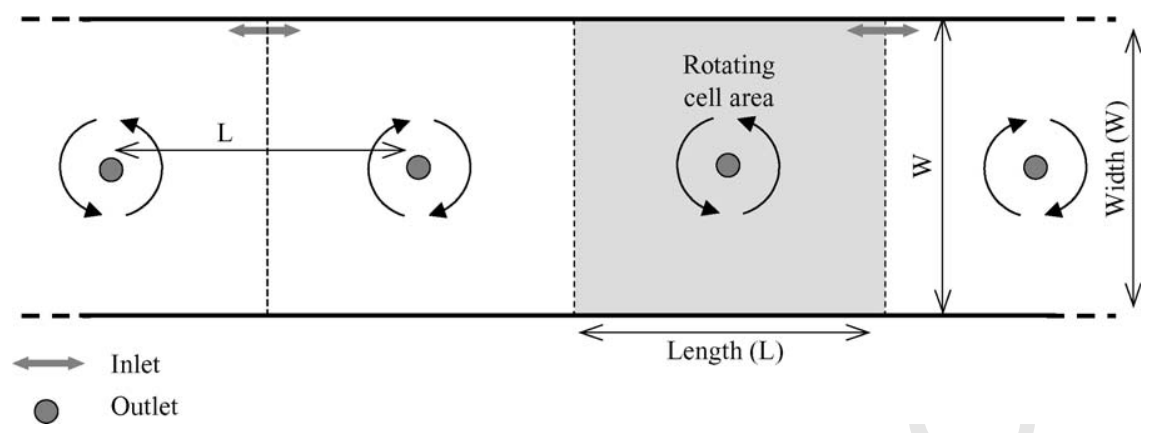

Fig. 1. Diagram of rectangular tank showing inlet and outlet placements, and rotating cell areas.

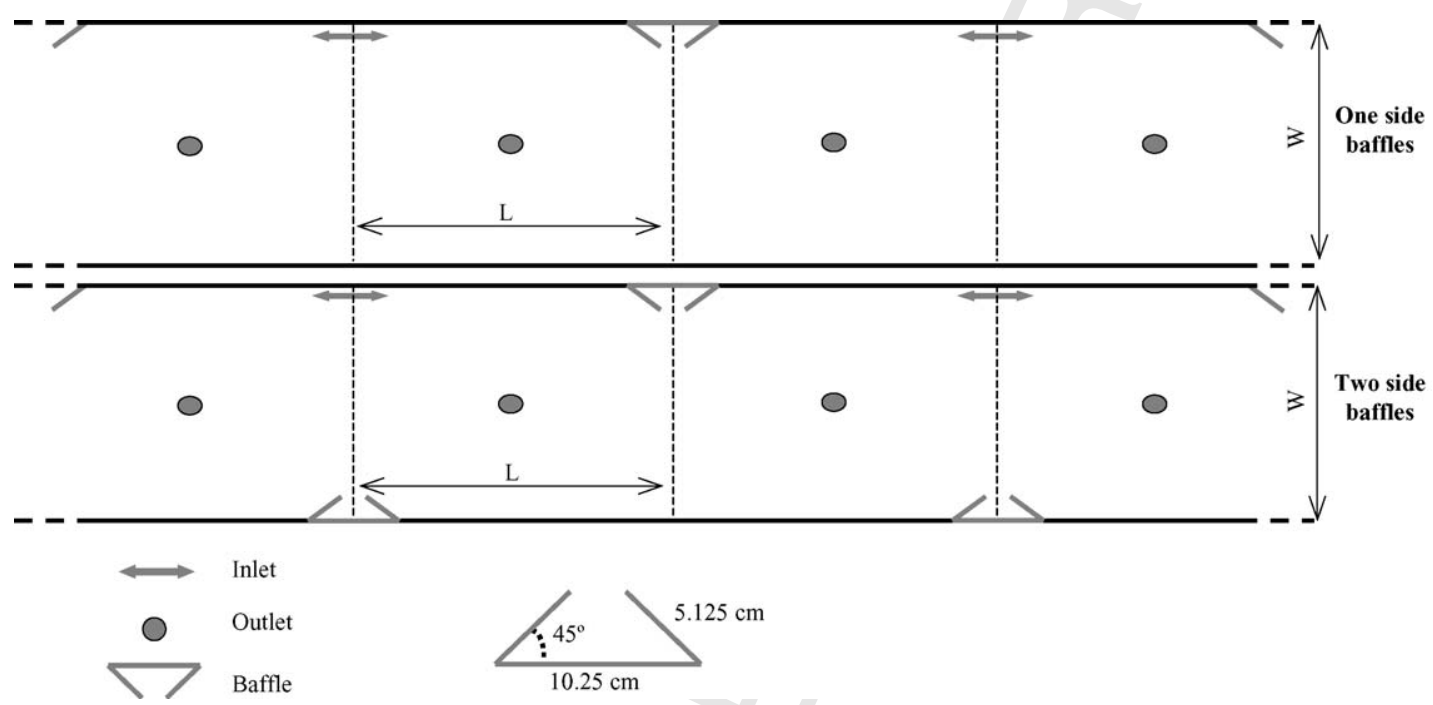

Fig. 2. Emplacement of baffles and entries in configurations with one and two side baffles.

The circular tank with a diameter of $49 \mathrm{~cm}$ had a single water entry and the drain was placed in the center of the tank bottom. The flow was then compared with those obtained in the rotating flow cells of rectangular tank configurations. Table 1 shows the geometric characteristics and flow rates of each configuration.

\subsection{Flow visualization and image analysis}

Particle Tracking Velocimetry technique (PTV) was used to obtain velocity fields in a horizontal plane at the midpoint of the water depth. Preliminary experiments conducted at different depths did not reveal significant differences between velocity fields.

Table 1

Geometric and hydraulic characteristics used in each configuration

\begin{tabular}{|c|c|c|c|c|}
\hline & Length/width ratio of mixing cell area $(L / W)$ & Baffles & Water inlet velocity $(\mathrm{m} / \mathrm{s})$ & Exchange rate $\left(\mathrm{h}^{-1}\right)$ \\
\hline \multirow[t]{8}{*}{ Rectangular tank } & \multirow[t]{3}{*}{0.95} & None & 0.301 & 5.94 \\
\hline & & One side & 0.589 & 5.94 \\
\hline & & Two sides & 0.589 & 5.94 \\
\hline & \multirow[t]{3}{*}{1.43} & None & 0.440 & 5.47 \\
\hline & & One side & 0.440 & 5.47 \\
\hline & & Two sides & 0.392 & 4.90 \\
\hline & \multirow[t]{2}{*}{1.91} & None & 0.637 & 5.94 \\
\hline & & One side & 0.637 & 5.94 \\
\hline Circular tank & 1 & None & 0.473 & 5.47 \\
\hline
\end{tabular}


PTV is a non-intrusive experimental method for investigating fluid flows, which allows the flow to be visualized by suspending neutrally buoyant tracer particles in the water volume. In this case, small particles of pliolita (Eliokem, pliolite S5E) with a density of approximately $1.05 \mathrm{~g} \mathrm{~cm}^{-3}$ and a diameter of around $0.5 \mathrm{~mm}$ were used. Sodium chloride was added to the tank to ensure the neutral buoyancy of the particles. A horizontal cross-section of the flow was illuminated at the midpoint of the water depth and the movement of the particles occupying the illuminated section was registered by a video camera placed $1.5 \mathrm{~m}$ above the water surface and digitized with a frame grabber card. Particle localization and tracking was achieved using specific software (Digimage) to determine the displacement, velocity and trace of each particle from sequences of frames. The data was summarized using an analysis package (Trk2Dvel) according to Dalziel (1999), which provided velocity maps of the mid-depth horizontal cross-section and longitudinal and lateral velocity profiles for each configuration. The average velocities for the horizontal section of a rotating flow cell were calculated for each experiment. Only intermediate cells were selected, in order to minimize the effect of an extra solid boundary in the end cells. A more detailed description of the application of PTV technique to flow characterization in fish production tanks can be found in Oca et al. (2004)

\subsection{Hydrodynamic analysis of rotating flow cells}

In a rectangular tank with several identical rotating flow cells, the impulse force from the inlet pipes to the cells $F_{\mathrm{i}}$ can be calculated using Eq. (1).

The impulse force $F_{\mathrm{i}}$ applied to the fluid in the tank that is moving at a velocity $V_{1}$, provides a power input $P_{\mathrm{i}}$, which can be calculated as:

$P_{\mathrm{i}}=F_{\mathrm{i}} V_{1}=\rho Q\left(V_{2}-V_{1}\right) V_{1}$

In a turbulent regime, the total resistive force to water circulation in the tank $F_{\mathrm{t}}$ can be calculated as:

$F_{\mathrm{t}}=C_{\mathrm{t}} A \rho \frac{V_{1}^{2}}{2}$

where $C_{\mathrm{t}}$ is the resistance coefficient of the tank and $A$ is the wet area.

And the power consumption $\left(P_{\mathrm{t}}\right)$ due to the resistive force $\left(F_{\mathrm{t}}\right)$ is:

$P_{\mathrm{t}}=F_{\mathrm{t}} V_{1}=C_{\mathrm{t}} A \rho \frac{V_{1}^{3}}{2}$
Assuming steady-state conditions, $P_{\mathrm{i}}$ is equal to $P_{\mathrm{t}}$. Under such conditions, the following expression gives the experimental determination of the resistance coefficient for a specific tank:

$C_{\mathrm{t}}=\frac{2 Q\left(V_{2}-V_{1}\right)}{A V_{1}^{2}}$

$C_{\mathrm{t}}$ will be useful for evaluating the resistance of water circulation as a function of tank geometry and inlet and outlet placements.

In order to compare the velocity maps and profiles of experiments conducted with different impulse forces, velocity vectors can be shown non-dimensionally $\left(V^{\prime}\right)$, using the following expression:

$V^{\prime}=V\left(\frac{2 Q\left(V_{2}-V_{1}\right)}{A}\right)^{-1 / 2}$

\section{Results and discussion}

\subsection{Velocity distribution}

Fig. 3 shows the flow patterns obtained in an intermediate single rotating cell area for each configuration analyzed; the vectors corresponding to water entries are not plotted because they are beyond the velocity range that can be detected by the equipment used. The velocity profiles on the longitudinal and lateral axes are shown in Figs. 4 and 5, respectively.

\subsubsection{Effect of length/width ratio}

Experiments with a length/width ratio $(L / W)$ of 0.95 show a single large vortex generated by each discharge entry which covers almost the entire cell area. If the $L / W$ ratio is increased from 0.95 to 1.43 , the main vortex continues to occupy most of the rotating cell area and no significant dead volumes are created in the tank. The velocity profile on the longitudinal axis showed higher velocities at the farthest point from the water inlet than at the point closest to the water inlet. Importantly, this increase in the $L / W$ ratio will make it easier for tanks to be constructed and adapted to a rotating cell flow pattern and requires fewer inlets and outlets for the same tank length.

When the $L / W$ ratio is increased to 1.91 , significant differences are observed in the flow pattern. The main vortex no longer covers the entire rotating cell area and significant dead areas with secondary vortices appear. Also, the vortex core is distorted and the velocities around it are very low. The center of the main vortex does not correspond to the center drain, since the vortex is displaced towards the opposite side of the discharge 


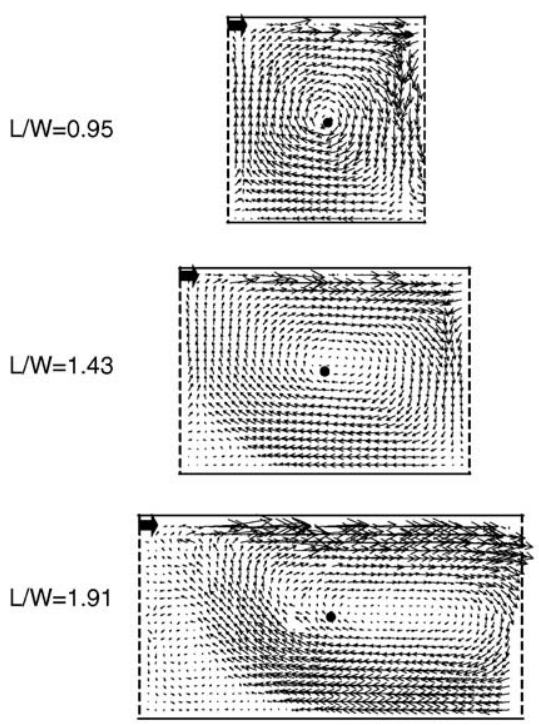

No baffles
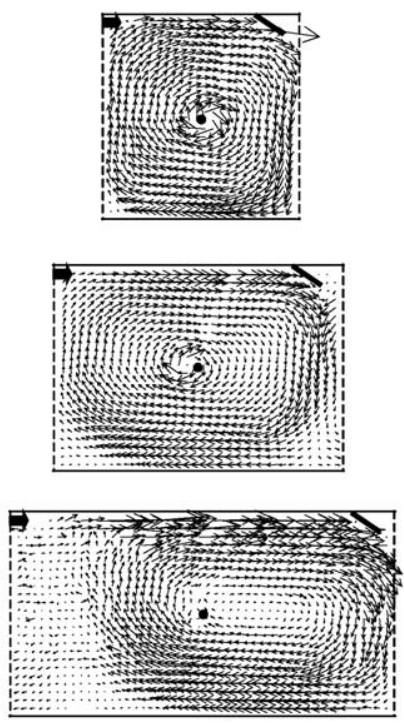

1 side baffles
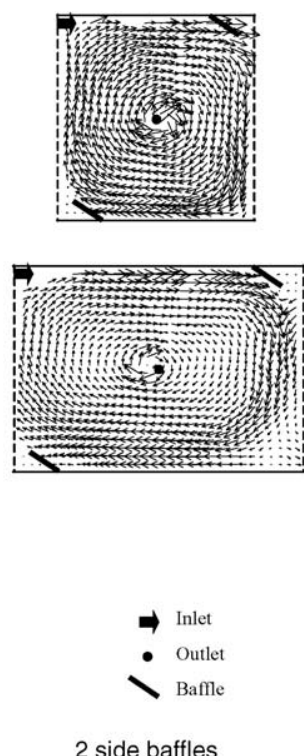

Fig. 3. Velocity field maps showing the flow patterns in a single rotating cell area, for configurations with $L / W$ at $0.95,1.43$ and 1.91 , and with 0,1 and 2 side baffles.

jet. Average velocities in the center of the vortex are very low and the flow patterns are very unstable, thus vortex sizes vary with time. Similar results were obtained by Uijttewaal (1999), Weitbrecht and Jirka (2001) when analyzing velocity patterns in the dead zones of shallow water flows. The aspect ratios determined the number of eddies, with a single eddy created when aspect ratios were close to one and a secondary eddy created when aspect ratios were close to 2. These characteristics clearly demonstrate that the highest length/width ratio $(L / W=1.91)$ is unsuitable for the design of rotating cell tanks.
260

261

262

263

264

265

266
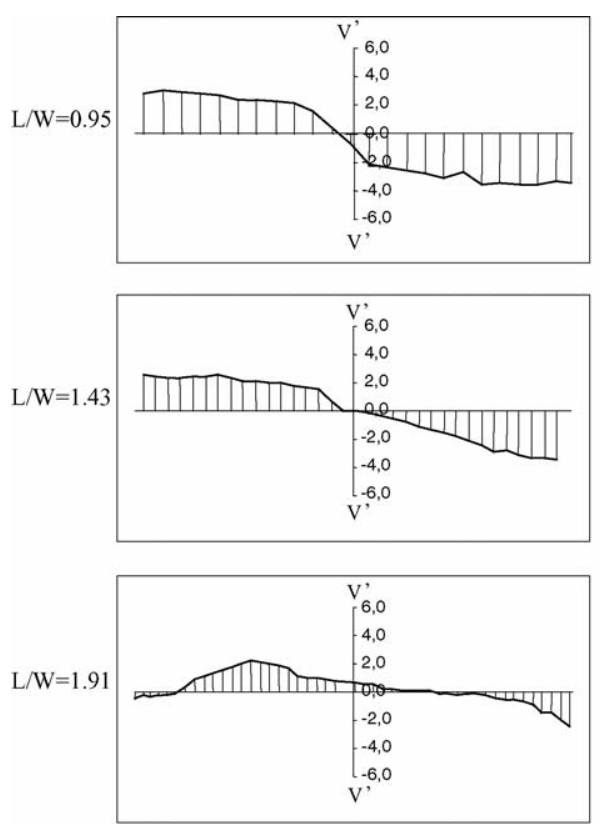

No baffles
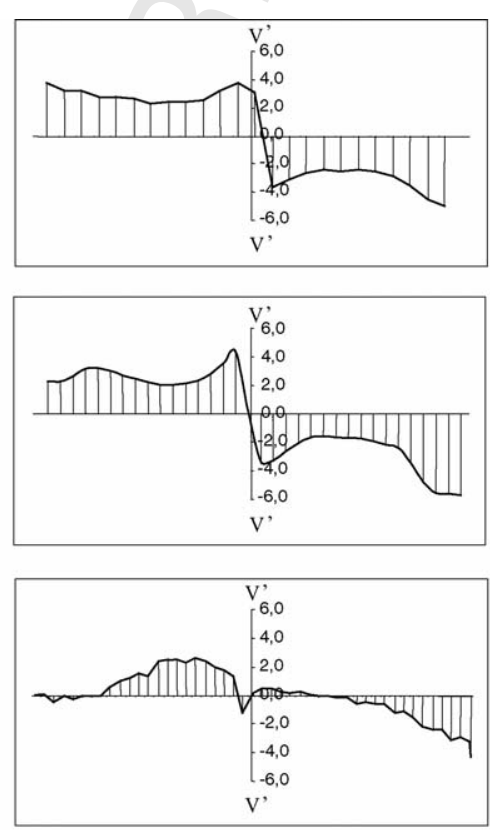

1 side baffles
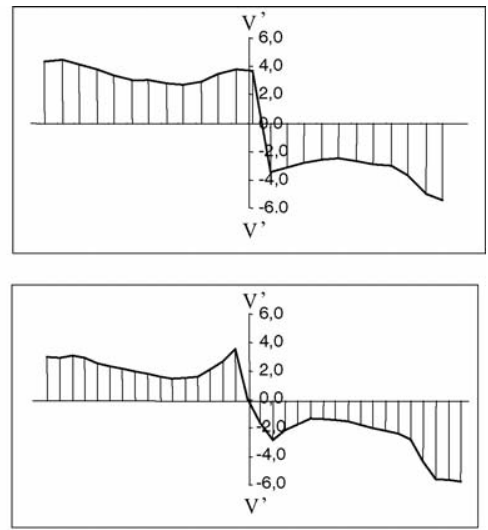

2 side baffles

Fig. 4. Non-dimensional velocity $\left(V^{\prime}\right)$ profiles in the longitudinal axis of the rotating cell area for each configuration. 

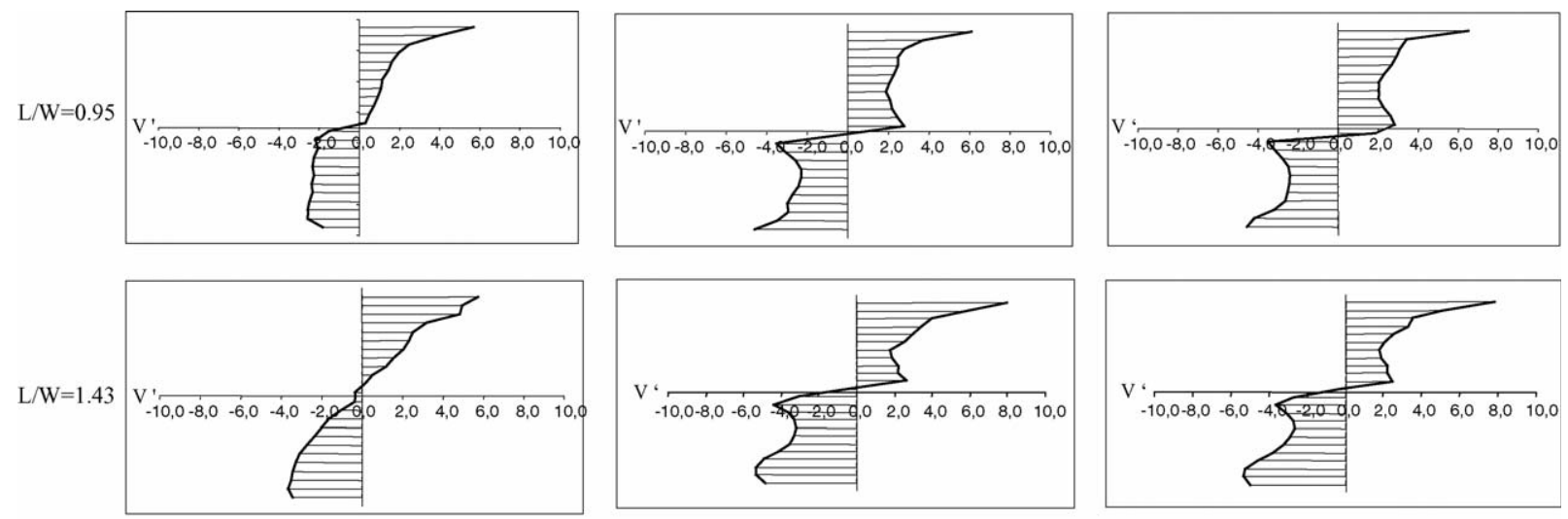

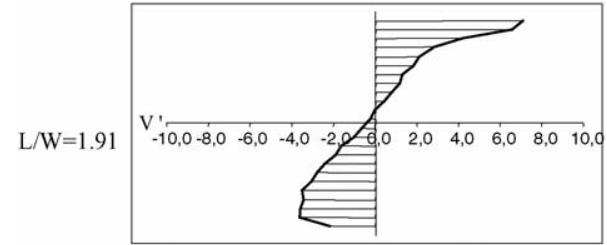

No baffles

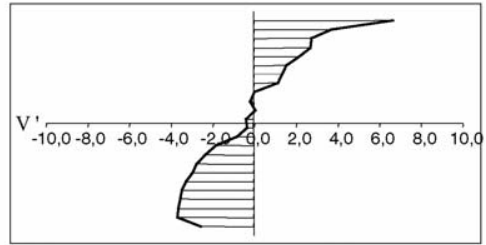

1 side baffles
2 side baffles

Fig. 5. Non-dimensional velocity $\left(V^{\prime}\right)$ profiles in the crossing axis of the rotating cell area for each configuration.

\subsubsection{Effect of baffles}

The presence of baffles proved to be important in generating high velocities in the area around the center drain. These higher velocities are a key factor in the self-cleaning properties of the tank.

Velocity profiles along the longitudinal and lateral axes are shown in Figs. 4 and 5 for configurations with baffles and $L / W$ ratios of 0.95 and 1.43 . Note that the maximum velocities are registered in the outer perimeter of the vortex and these progressively drop to constant velocities in the central part of the vortex radius. The velocity increases again in the inner part of the vortex, due to effect of the free vortex formed by the water outlet. This increase can also be observed in velocity maps (Fig. 3). This type of flow pattern is very similar to that obtained in the equivalent experiment with a circular tank (Fig. 6) and is in good agreement with the circular tank flow described by Tvinnereim and Skybakmoen (1989) and Rasmussen and McLean (2004), with high relative velocities observed close to the central water outlet. In an experiment using a dual drain tank that discharged the majority of its flow through a drain located in its side wall and a smaller part through a center bottom drain, Davidson and Summerfelt (2004) found that water velocities near the tank center increased with higher drain-bottom flow rates.

No significant differences are observed between experiments using baffles in a single wall and others using baffles in both walls. Nevertheless, in experiments
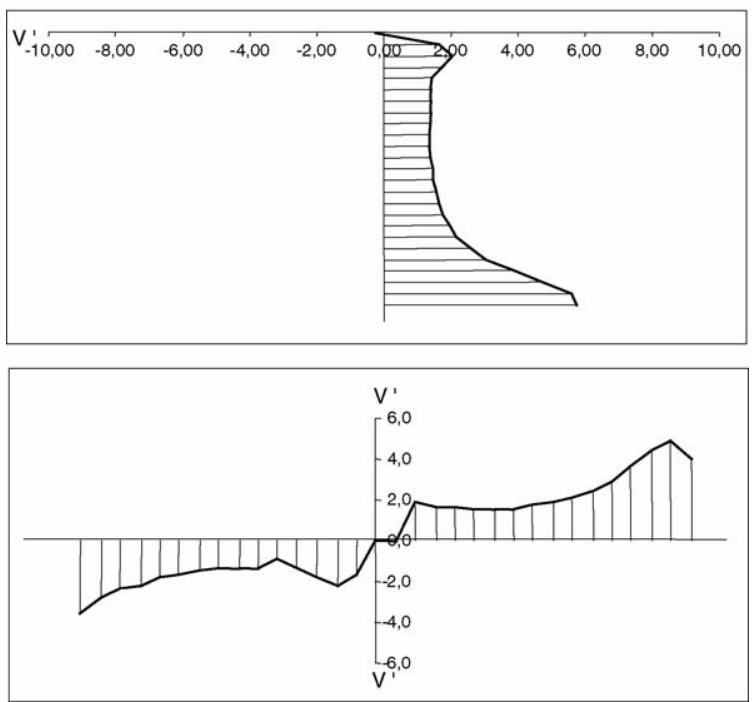

Fig. 6. Flow pattern and non-dimensional velocity $\left(V^{\prime}\right)$ profiles in longitudinal and crossing axes in the circular tank. 
where no baffles are used, velocities decrease from the perimeter of the rotating cell to the water outlet, and the effect of the free vortex on velocity profiles is small with a $L / W$ of 0.95 and undetectable with higher $L / W$ ratios.

With a $L / W$ ratio of 1.91 , the presence of baffles makes no appreciable contribution to improving water velocity distribution.

\subsection{Resistance coefficient of the tank $C_{t}$}

\subsubsection{Influence of baffles and $L / W$ ratio}

The resistance coefficient of each configuration $C_{\mathrm{t}}$ (Eq. (1)) is shown in Table 2.

The values obtained are in excellent agreement with some of the qualitative observations described above. In rectangular tank configurations, lower $C_{\mathrm{t}}$ values are obtained with $L / W$ ratios of 0.95 and 1.43 and with the inclusion of baffles. The presence of baffles in the same wall as the water inlets (one side baffles) decreases $C_{\mathrm{t}}$ values by approximately $30-35 \%$. These results indicate that baffles placed in the midpoint of two opposite water inlets are important in driving the two water currents produced and in diminishing the friction losses caused by the collision of the two currents. The presence of a second group of baffles in the wall where no entries are placed (two side baffles) produces small variations in $C_{\mathrm{t}}$ values. The values obtained in experiments with $L / W$ at 0.95 and 1.43 and with the inclusion of baffles are very close to those obtained in tests with a circular tank. When $L / W$ is increased to $1.91, C_{\mathrm{t}}$ values rise dramatically and are not visibly affected by the presence of baffles.

\subsubsection{Expected results in larger scale tanks}

The Reynolds numbers in these experiments, defined in terms of hydraulic diameter (approximately four times the water depth), were in the region of 6000 , i.e., showing turbulent flow. Under these conditions, the flow pattern observed should be applicable to larger tanks (Tvinnereim, 1988; Tvinnereim and Skybakmoen, 1989; Chanson, 1999; Weitbrecht and Jirka,

Table 2

Resistance coefficient $\left(C_{\mathrm{t}}\right)$ obtained for each tank configuration

\begin{tabular}{lllll}
\hline & $L / W$ & $C_{\mathrm{t}}$ & & \\
\cline { 3 - 5 } & & $\begin{array}{l}\text { No } \\
\text { baffles }\end{array}$ & $\begin{array}{l}\text { One side } \\
\text { baffles }\end{array}$ & $\begin{array}{l}\text { Two side } \\
\text { baffles }\end{array}$ \\
\hline Rectangular tank & 0.95 & 0.14 & 0.09 & 0.08 \\
& 1.43 & 0.13 & 0.09 & 0.09 \\
Circular tank & 1.91 & 0.18 & 0.17 & - \\
\hline
\end{tabular}

2001). Nevertheless, $C_{\mathrm{t}}$ values can also be affected by the lower Reynolds numbers found in small-scale tanks, due to the greater importance of viscous effects (Chanson, 1999). The $C_{\mathrm{t}}$ values given here are useful for comparing different configurations, but full-scale research trials are necessary in order to determine definitive $C_{\mathrm{t}}$ values. These experiments would make it possible to compare not only the tank configuration, but also the influence of the water inlet arrangement, which has been shown to affect water velocities (Tvinnereim and Skybakmoen, 1989; Timmons et al., 1998).

Experiments conducted by Watten et al. (2000) in a rectangular tank $0.7 \mathrm{~m}$ deep with rotating cells $2.4 \mathrm{~m}$ long and wide, 1.3 exchanges per hour, an inlet velocity of $3.24 \mathrm{~m} / \mathrm{s}, 4$ water entries per rotating cell and without baffles, produced an average velocity of $0.12 \mathrm{~m} / \mathrm{s}$. The $C_{\mathrm{t}}$ value obtained from this data would be approximately 0.07 - very similar to the values obtained in our small-scale experiments.

\subsubsection{Control of velocities}

By calculating a $C_{\mathrm{t}}$ value for the tank, it is easy to obtain the desired average velocities by adjusting the injected water flow rate $(Q)$ and the water inlet velocity $\left(V_{2}\right)$. From Eq. (5) we can write:

$V_{1}=\left(\frac{2 Q\left(V_{2}-V_{1}\right)}{A C_{\mathrm{t}}}\right)^{1 / 2}$

When the value of $V_{2}$ is much greater than that of $V_{1}$, this can be approximated as:

$V_{1} \approx\left(\frac{2 Q V_{2}}{A C_{\mathrm{t}}}\right)^{1 / 2}$

$Q$ can be related to $V_{2}$ if the total area of inlet openings $\left(A_{0}\right)$ are known:

$Q=V_{2} A_{0}$

Eq. (8) can be re-written as follows:

$V_{1} \approx\left(\frac{2 A_{0}}{A C_{\mathrm{t}}}\right)^{1 / 2} V_{2}$

This shows that for a specific tank, a specific discharge device and a specific water depth, average water velocities will be roughly proportional to water inlet velocities. As an example, let us consider a tank $16 \mathrm{~m}$ long, $3 \mathrm{~m}$ wide and $1 \mathrm{~m}$ deep, with four rotating cells (area: $4 \mathrm{~m} \times 3 \mathrm{~m}$ ) and a discharge jet orifice with a diameter of $40 \mathrm{~mm}$. If the required $C_{\mathrm{t}}$ were 0.08 , the water discharge velocity needed to obtain an average velocity of $15 \mathrm{~cm} / \mathrm{s}$ would be $378 \mathrm{~cm} / \mathrm{s}$, which corresponds to a flow rate of $19 \mathrm{~L} / \mathrm{s}$ and 1.43 water exchanges per hour. 
Relatively high, easily regulated average velocities with low energy consumption are usually obtained only with circular tanks. The tank configurations analyzed here would provide similar advantages in a rectangular tank.

The water velocity must be high enough to make the tank self-cleaning, but not greater than the desired fish swimming speed. The velocities required for selfcleaning have been estimated by various authors (Burrows and Chenoweth, 1970; Tvinnereim, 1988; Timmons and Youngs, 1991). The recommended velocities vary greatly according to faeces characteristics (Brinker et al., 2005) and range between 4 and $30 \mathrm{~cm} / \mathrm{s}$. These studies only considered the effect of water flow in the tank, disregarding the possible effect of turbulence generated by the fish, although this has been analyzed by other researchers (Burley and Klapsis, 1985, 1988; Watten et al., 2000; Rasmussen et al., 2005). Several authors have analyzed the optimal velocities for maintaining fish health, muscle tone and respiration, obtaining values of 0.5-2 times fish body length per second (Timmons and Youngs, 1991; Losordo and Westers, 1994).

\section{Conclusions}

Rotating flow cells in rectangular tanks can be generated using only a single inlet per cell. These cells may have very similar flow patterns to those obtained in circular tanks, if certain design criteria are followed in the placement of water inlets and outlets and the use of baffles to drive the water current.

The tank resistance coefficient $\left(C_{\mathrm{t}}\right)$ has been demonstrated as a useful tool for the evaluation of tank configurations in both rectangular tanks with rotating cells and in circular tanks. $C_{\mathrm{t}}$ values are very useful for adjusting the desired average velocity in the tank.

Increasing the distance of water inlets from $L / W 0.95$ to $L / W 1.43$ did not have a significant effect on the flow characteristics, the velocities achieved or the presence of dead volumes. A higher $L / W$ value will make construction of rectangular tanks with rotating cells easier, since the number of water inlets and outlets required is reduced by $30 \%$. A $L / W$ ratio of 1.91 would dramatically reduce flow uniformity and create significant dead volumes.

Baffles attached obliquely to the same wall as the discharge jets, exactly in the midpoint between two opposite water inlets, contribute significantly to an in increase in water velocities, particularly in the area closer to the center of the vortex where the water outlet must be placed. The flow pattern obtained under these conditions was very similar to those observed in circular tanks; the formation of a free vortex increasing the water velocity around the water outlet will allow the use of dual drains to separate suspended solids and to prevent sedimentation on the tank bottom.

In order to maintain the advantages of rectangular tanks relating to easier fish manipulation, it should be possible to turn baffles to the wall and to remove water inlets so as to leave the cross section free along the entire tank. An alternative water inlet and outlet should be constructed in order to allow water replacement during periods of fish manipulation.

\section{Acknowledgement}

This research was financed by the "Centre de Referència en Aqüicultura de la Generalitat de Catalunya”.

\section{References}

Barnes, M.E., Sayler, W.A., Cordes, R.J., 1996. Baffle usage in covered raceways. Prog. Fish-Cult. 58, 286-288.

Boersen, G., Westers, H., 1986. Waste solids control in hatchery raceways. Prog. Fish-Cult. 48, 151-154.

Brinker, A., Koppe, W., Rösch, R., 2005. Optimised effluent treatment by stabilised trout faeces. Aquaculture 249, 125-144.

Burley, R., Klapsis, A., 1985. Flow distribution studies in fish rearing tanks. Part 2. Analysis of hydraulic performance of $1 \mathrm{~m}$ square tanks. Aquacult. Eng. 4, 113-134.

Burley, R., Klapsis, A., 1988. Making the most of your flow (in fish rearing tanks). In: Proceedings of the Conference: Aquaculture Engineering, Technologies for the Future, Sterling, Scotland, IchemE, Symposium Series 111, EFCE, Publication Series 66, Rugby, UK, pp. 211-223.

Burrows, R.E., Chenoweth, H.H., 1970. The rectangular circulating pond. Prog. Fish-Cult. 32, 80-97.

Chanson, H., 1999. The Hydraulics of Open Channel Flow. Butterworth Heineman, Oxford, 495 pp.

Davidson, J., Summerfelt, S., 2004. Solids flushing, mixing, and water velocity profiles within large $\left(10\right.$ and $\left.150 \mathrm{~m}^{3}\right)$ circular "Cornelltype" dual-drain tanks. Aquacult. Eng. 32, 245-271.

Dalziel, S., 1999. Two-dimensional particle tracking. DL Research Papers 1993-1999.

Kindschi, G.A., Thompson, R.G., Mendoza, A.P., 1991. Use of raceway baffles in rainbow trout culture. Prog. Fish-Cult. 53, 97-101.

Lareau, S., Champagne, R., Ouellet, G., Gilbert, E., Vandenber, G., 2004. Rapport sur les missions d'évaluation de la technologie danoise pour l'élevage en eau douce des salmonidés.In: Société de Recherche et de développement en aquaculture continental (SORDAC), Québec, Canada.

Levenspiel, O., 1979. The Chemical Reactor Omnibook. OR OSU Book Stores, Corvallis, $600 \mathrm{pp}$.

Losordo, T.M., Westers, H., 1994. System carrying capacity and flow estimation. In: Timmons, M.B., Losordo, T.M. (Eds.), Aquaculture Water Systems: Engineering Design and Management. Elsevier, New York, pp. 9-60. 
Lunde, T., Skybakmoen, S., Schei, I., 1997. Particle Trap. US Patent $5,636,595$

Masaló, I., Oca, J., 2004. Analysis of Residence Time Distribution (RTD) in aquacultural tanks, and correspondence with the flow pattern characterized using Particle Traking Velocimetry (PTV) techniques. In: European Aquaculture Society (Ed.), Biotechnologies for Quality. Aquaculture Europe'04, 20-22 October 2004, Barcelona, Spain. EAS Special Publication no. 34, pp. 538-539.

Oca, J., Masaló, I., Reig, L., 2004. Comparative analysis of flow patterns in aquaculture rectangular tanks with different water inlet characteristics. Aquacult. Eng. 31, 221-236.

Rasmussen, M.R., McLean, E., 2004. Comparision of two differents methods for evaluating the hydrodynamic performance of an industrial-scale fish-rearing unit. Aquaculture 242, 397-416.

Rasmussen, M.R., Laursen, J., Craig, S.R., McLean, E., 2005. Do fish enhance tank mixing? Aquaculture 250, 162-174.

Ross, R.M., Watten, B.J., Krise, W.F., DiLauro, M.N., 1995. Influence of tank design and hydraulic loading on the behaviour, growth, and metabolism of rainbow trout (Oncorhynchus mykiss). Aquacult. Eng. 14, 29-47.

Ross, R.M., Watten, B.J., 1998. Importance of rearing-unit design and stocking density to the behaviour, growth and metabolism of lake trout (Salvelinus namaycush). Aquacult. Eng. 19, 41-56.

Schei, I., Skybakmoen, S., 1998. Control of water quality and growth performance by solids removal and hydraulic control in rearing tanks. In: Fisheco'98, First International Symposium on Fisheries and Ecology, Trabzon, Turkey, 2-4 September.

Summerfelt, S.T., Davidson, J., Timmons, M.B., 2000. Hydrodynamics in the "Cornell-type" dual-drain tank. In: Libey, G.S., Timmons, M.B. (Eds.), The Third International Conference of Recirculating Aquaculture, Virginia Polytechnic Institute and State University, Roanoke, VA, 22-23 July, pp. 160-166.

Timmons, M.B., Youngs, W.D., 1991. Considerations on the design of raceways, from ASAE Special Publication \#701: Aquaculture Systems Engineering, Proceedings from World Aquaculture Society, World Aquaculture 91, 15-22 June, San Juan, Puerto Rico.
Timmons, M.B., Summerfels, S.T., Vinci, B.J., 1998. Review of circular tank technology and managment. Aquacult. Eng. 18, 51-69.

True, B., Johnson, W., Chen, S., 2004. Reducing phosphorous discharge from flow-through aquaculture II: Hinged and moving baffles to improve waste transport. Aquacult. Eng. 32, 145-160.

Tvinnereim, K., 1988. Design of water inlets for closed fish farms. In: Proceedings of the Conference: Aquaculture Engineering: Technologies for the Future. Sterling, Scotland. IchemE Symposium Series 111, EFCE Publication Series 66, Rugby, UK, pp. 241-249.

Tvinnereim, K., Skybakmoen, S., 1989. Water exchange and selfcleaning in fish-rearing tanks. In: Aquaculture-A Biotechnology in Progress, European Aquaculture Society, Bredene, Belgium.

Uijttewaal, W.S.J., 1999. Groyne field velocity patterns determined with particle tracking velocimetry. In: Proceedings of the 28th IAHR Congress, Graz, Austria.

Van Toever, E., 1997. Water treatment system particularly for use in aquaculture. US Patent 5,593,574.

Wagner, E.J., 1993. Evaluation of a new baffle design for solid waste removal from hatchery raceways. Prog. Fish-Cult. 55, 43-47.

Watten, B.J., Beck, L.T., 1987. Comparative hydraulics of rectangular cross-flow rearing unit. Aquacult. Eng. 6, 127-140.

Watten, B.J., Johnson, R.P., 1990. Comparative hydraulics and rearing trial performance of a production scale cross-flow rearing unit. Aquacult. Eng. 9, 245-266.

Watten, B.J., Honeyfield, D.C., Schwartz, M.F., 2000. Hydraulic characteristics of a rectangular mixed-cell rearing unit. Aquacult. Eng. 24, 59-73.

Weitbrecht, V., Jirka, G.H., 2001. Flow patterns and exchange processes in dead zones of rivers. In: Proceedings of the 29th IAHR Congress, Beijing, China.

Wong, K.B., Piedrahita, R.H., 2003. Prototype testing of the appurtenance for settleable solids in-raceway separation (ASSISST). Aquacult. Eng. 27, 273-293.

Woodward, J.J., Smith, L.S., 1985. Exercise training and the stress response in rainbow trout, Salmo gairdneri Richardson. J. Fish Biol. 26, 435-447. 